\title{
AVALIAÇÃO DA PRODUÇÃO DE GRÃOS E CARACTERÍSTICAS AGRONÔMICAS EM GENÓTIPOS DE TRIGO, EM 1999 E $2000^{(1)}$
}

\author{
JÚLIO CÉSAR MISTRO ${ }^{(2)}$; CARLOS EDUARDO DE OLIVEIRA CAMARGO(3,4)
}

\begin{abstract}
RESUMO
Avaliaram-se 18 linhagens e duas cultivares de trigo, em experimentos instalados em condição de irrigação por aspersão, solo corrigido e adubado, na Estação Experimental de Agronomia de Tatuí (SP), em 1999 e 2000. Determinaram-se as seguintes características agronômicas: produção de grãos, altura das plantas, ciclo - em dias - da emergência ao florescimento, número de grãos por espiga, massa de cem grãos e comprimento, largura e espessura dos grãos. Correlaçôes simples entre todas essas características foram estimadas para os dois experimentos. As geadas ocorridas na época de enchimento dos grãos, em 2000, ocasionaram em todos os genótipos de trigo redução nas produção de grãos e, na maioria dos genótipos, no número de grãos por espiga e na massa de cem grãos. Os genótipos mais altos tenderam ser menos afetados pela ação das geadas. Destacaram-se, em 1999, o genótipo 9 (BANACORA T 88) pelo porte baixo; os genótipos 2 (KAUZ*2/MNV//KAUZ), 9 e 14 (WH 542) pelo maior número de grãos por espiga e, o genótipo 3 (SAWGAI) pela maior massa de cem grãos, constituindo-se em fontes genéticas dessas características para programas de cruzamentos de trigo.

Palavras-chave: Triticum aestivum L., geada, altura da planta, massa de cem grãos, correlações.
\end{abstract}

\section{ABSTRACT \\ GRAIN YIELD AND AGRONOMIC CHARACTERISTICS EVALUATIONS IN WHEAT GENOTYPES IN 1999 AND 2000}

Eighteen wheat lines and two cultivars were evaluated in trial carried out under sprinkler irrigation, limed and fertilized soils, at the Tatuí Agronomy Experimental Station, State of São Paulo, Brazil during 1999 and 2000. Grain yield, plant height, number of days from emergence to flowering, number of grains per spike, 100 grain weight, grain length, width and thickness were evaluated. Simple correlations between these characteristics were estimated. The occurrence of frosts at grain filling period, in 2000, resulted in grain yield reduction in all genotypes, reduction in the number of grains per spike, and also in 100 grain weight for the majority of the genotypes. The highest genotypes showed a tendency to be less affected by the frosts. The genotype 9 (BANACORA T 88) exihibited short plants; the genotypes 2 (KAUZ*2/MNV//KAUZ), 9 and 14 (WH 542) presented high number of grains per spike and the genotype 3 (SAWGAI) high 100 grain weight, in the experiment seeded in 1999. These genotypes could be used as genetic sources in crossing programs, where these traits would be desired.

Key words: Triticum aestivum L., frost, plant height, 100 grain weight, correlations.

( ${ }^{1}$ ) Parte da dissertação de Mestrado em Melhoramento Genético Vegetal do primeiro autor, apresentada ao Instituto Agronômico (IAC). Recebido para publicação em 19 de setembro de 2001 e aceito em 26 de fevereiro de 2002.

( ${ }^{2}$ ) Mestrando com bolsa da FAPESP, Centro de Análise e Pesquisa Tecnológica do Agronegócio de Grãos e Fibras, Instituto Agronômico (IAC), Caixa Postal 28, 13001-970 Campinas (SP).

$\left({ }^{3}\right)$ Centro de Análise e Pesquisa Tecnológica do Agronegócio de Grãos e Fibras, IAC.

$\left({ }^{4}\right)$ Com bolsa de produtividade em pesquisa do CNPq. 


\section{INTRODUÇÃO}

Visando ao aumento da produtividade do trigo, modernas técnicas de cultivo têm sido utilizadas; destacam-se entre elas: emprego da irrigação por aspersão, adubação nitrogenada, colheita mecânica, genótipos de trigo com porte baixo - resistentes ao acamamento, com palha forte e responsivos às adubaçôes.

A incidência de geadas, em alguns anos no Brasil, tem ocasionado redução significativa na produção de grãos na cultura do trigo (Triticum aestivum L.), acarretando elevados prejuízos econômicos aos triticultores e aumentando as despesas com a importação deste cereal.

BANATH E Single (1976) estimaram a perda de mais de $50 \%$ do potencial produtivo do trigo devido aos danos ocasionados pelas geadas, na Austrália. Os mesmos autores constataram a redução do número de grãos por espiga, da massa e da qualidade dos grãos em cultivos de trigo submetidos a baixas temperaturas em casas de vegetação.

A planta do trigo parece responder de maneira diversa às injúrias causadas pela geada, dependendo do estádio de desenvolvimento em que ela se encontra (SCHEEREN, 1982). O trigo é sensível à temperatura do ar entre $1^{\circ} \mathrm{C}$ e $2{ }^{\circ} \mathrm{C}$ abaixo de zero durante o florescimento (МотA, 1982). Essas temperaturas ocasionam o chochamento dos grãos devido à esterilidade do pólen. Outro período crítico é o da formação dos grãos; observa-se que as temperaturas que variam de $2^{\circ} \mathrm{C} \mathrm{a} 4^{\circ} \mathrm{C}$ abaixo de zero reduzem a produção de grãos.

SCHEeren (1982), avaliando genótipos de trigo afetados pela geada, verificou que o estádio da planta mais sensível é o do espigamento até o início da formação dos grãos. Quando houve estrangulamento nos colmos, notou-se um impedimento na circulação da seiva para os grãos, além da diminuição da síntese de fotoassimilados causados pela queima das folhas.

Segundo Single (1971), os principais sintomas e danos ocasionados pela geada são o impedimento da formação e do enchimento dos grãos, estrangulamento do colmo, além da queima das folhas.

No presente trabalho, 20 genótipos de trigo foram avaliados quanto à produção de grãos, altura das plantas e outras características agronômicas, em condiçōes de irrigação por aspersão, na Estação Experimental de Agronomia de Tatuí, em 1999 e 2000, respectivamente, em situações climáticas normais e sob efeito de geadas.

\section{MATERIAL E MÉTODOS}

Avaliaram-se de genótipos de trigo, os quais foram semeados, em 27 de abril de 1999 e 12 de abril de 2000, em irrigação por aspersão, na Estação Experimental de Agronomia de Tatuí, Instituto Agronômico (IAC).

Cada experimento foi constituído por 20 genótipos (Quadro 1), sendo 18 linhagens de trigo introduzidas do Centro Internacional de Melhoramento de Milho e Trigo (CIMMYT), México e duas cultivares-controle recomendadas para semeadura no Estado de São Paulo: IAC-24 e IAC-289, cujas características foram descritas por Felicio et al. (1988, 1994).

Retiraram-se amostras compostas do solo no local de cada experimento, na profundidade de 0 a $20 \mathrm{~cm}$, nos dois anos considerados. As análises químicas foram realizadas no Laboratório do Centro de Solos e Recursos Agroambientais do IAC (Quadro 2).

De acordo com as tabelas de adubação do IAC e em função das análises do solo (RAIJ et al., 1997) efetuaramse, nos experimentos citados, adubações de semeadura de $330 \mathrm{~kg} \cdot \mathrm{ha}^{-1}$ de 4-14-8 ( $\mathrm{N}, \mathrm{P}_{2} \mathrm{O}_{5}$ e $\left.\mathrm{K}_{2} \mathrm{O}\right)$, além de uma adubação de cobertura com sulfato de amônio (40 $\mathrm{kg} \cdot \mathrm{ha}^{-1}$ de N), no início do perfilhamento, aos 30-40 dias após a emergência das plantas.

Cada experimento constituiu-se de 80 parcelas, cada uma formada por seis linhas de $3 \mathrm{~m}$ de comprimento, espaçadas de $0,20 \mathrm{~m}$. A semeadura foi feita à base de 80 sementes viáveis por metro, equivalendo a 1.440 sementes por parcela, com uma área útil de $3,6 \mathrm{~m}^{2}$. $\mathrm{O}$ delineamento estatístico foi o de blocos ao acaso, com quatro repetições.

Iniciou-se a irrigação por aspersão logo após a semeadura dos experimentos, em intervalos de 7 a 10 dias (quando não ocorreram chuvas), e o término sucedeu próximo à maturação das plantas. Aplicou-se, aproximadamente, uma lâmina de $20 \mathrm{~mm}$ em cada irrigação. Realizaram-se, em cada parcela nos dois experimentos, as seguintes avaliações agronômicas:

Produção de grãos: pesou-se, em gramas, a produção total de grãos, a qual foi transformada em kg.ha ${ }^{-1}$.

Altura das plantas: mediu-se a distância (em centímetros) do nível do solo ao ápice da espiga, excluindo as aristas, no início da maturação das plantas.

Grãos por espiga: contou-se o número médio de grãos de cinco espigas, tomadas ao acaso.

Massa de cem grãos: considerou-se a massa, em gramas, do número total de grãos das cinco espigas tomadas ao acaso, o qual foi transformado para massa de cem grãos.

As características agronômicas a seguir foram avaliadas, em cada parcela, somente em 2000:

Ciclo da emergência ao florescimento: realizou-se a contagem do número de dias da emergência das plântulas ao pleno florescimento.

Dimensão dos grãos: mediu-se, em milímetros, o comprimento, a largura e a espessura média de dez grãos, tomados ao acaso. 
Quadro 1. Genótipos de trigo avaliados nos experimentos instalados em condição de irrigação por aspersão, na Estação Experimental de Agronomia de Tatuí, em 1999 e 2000

\begin{tabular}{|c|c|c|}
\hline Genótipos & Origem $^{(1)}$ & Genealogia \\
\hline 1 & $5^{\text {th }}$ HTWYT - T 36 & CMH 8 DA.542 / CNO - 79 \\
\hline 2 & $5^{\text {th }}$ HTWYT - T 45 & $\mathrm{KAUZ}^{*} 2$ / MNV // KAUZ \\
\hline 3 & $5^{\text {th }}$ HTWYT - T 49 & SAWGAI \\
\hline 4 & $5^{\text {th }}$ HTWYT - T 44 & $\mathrm{KAUZ} * 2$ / MNV // KAUZ \\
\hline 5 & $5^{\text {th }}$ HTWYT - T 26 & FCT / 3 / GOV / AZ // MUS / 4 / DOVE / BUC \\
\hline 6 & $5^{\text {th }}$ HTWYT - T 30 & HAHN / TURACO // TURACO \\
\hline 7 & $5^{\text {th }}$ HTWYT - T 20 & CHIL / BUC \\
\hline 8 & $5^{\text {th }}$ HTWYT - T 42 & $\mathrm{KAUZ}^{*} 2$ / MYNA // KAUZ \\
\hline 9 & $5^{\text {th }}$ HTWYT - T 5 & BANACORA T 88 \\
\hline 10 & $5^{\text {th }}$ HTWYT - T 3 & OPATA M 85 \\
\hline 11 & $5^{\text {th }}$ HTWYT - T 17 & CETTIA \\
\hline 12 & $5^{\text {th }}$ HTWYT - T 14 & PRINIA \\
\hline 13 & $5^{\text {th }}$ HTWYT - T 12 & TURACO \\
\hline 14 & $5^{\text {th }}$ HTWYT - T 7 & WH 542 \\
\hline 15 & $5^{\text {th }}$ HTWYT - T 24 & URES / JUN // KAUZ \\
\hline 16 & $5^{\text {th }}$ HTWYT - T 37 & KAUZ * 2 / TRAP // KAUZ \\
\hline 17 & $5^{\text {th }}$ HTWYT - T 32 & HAHN / 2 * WEAVER \\
\hline 18 & $5^{\text {th }}$ HTWYT - T 34 & PARA 2 // JUP / BJY / 3 / VEE / JUN / 4 / 2*KAUZ \\
\hline IAC-24 & & IAS-51 x ISWRN 597-70 \\
\hline IAC-289 & & KAVKAZ/BUHO“S”//KALYASONA/BLUEBIRD \\
\hline
\end{tabular}

(1) HTWYT = Heat Tolerant Wheat Yield Trial (Ensaio de linhagens de trigo tolerantes ao calor) originário do CIMMYT, México.

Quadro 2. Resultados das análises de solo dos experimentos instalados em condição de irrigação por aspersão, na Estação Experimental de Agronomia de Tatuí, em 1999 e 2000, na profundidade de 0 a $20 \mathrm{~cm}^{(1)}$

\begin{tabular}{lr}
\hline Determinaçōes & Tatuí \\
\hline P resina $\left(\mathrm{mg}^{\mathrm{kg}} \mathrm{kg}^{-1}\right)$ & 58,0 \\
$\mathrm{M} . \mathrm{O} \cdot\left(\mathrm{g}_{\mathrm{kg}} \mathrm{kg}^{-1}\right)$ & 20,0 \\
$\mathrm{pH}\left(\mathrm{CaCl}_{2}\right)$ & 5,2 \\
$\mathrm{~K}\left(\mathrm{mmol}_{c} \cdot \mathrm{dm}^{-3}\right)$ & 7,6 \\
$\mathrm{Ca}\left(\mathrm{mmol}_{\mathrm{c}} \cdot \mathrm{dm}^{-3}\right)$ & 60,0 \\
$\mathrm{Mg}\left(\mathrm{mmol}_{\mathrm{c}} \cdot \mathrm{dm}^{-3}\right)$ & 13,0 \\
$\mathrm{H}+\mathrm{Al}\left(\mathrm{mmol}_{\mathrm{c}} \cdot \mathrm{dm}^{-3}\right)$ & 34,0 \\
$\mathrm{~S}\left(\mathrm{mmol}_{\mathrm{c}} \cdot \mathrm{dm}^{-3}\right)$ & 80,6 \\
$\mathrm{~T}\left(\mathrm{mmol}_{\mathrm{c}} \cdot \mathrm{dm}^{-3}\right)$ & 114,6 \\
$\mathrm{~V} \%$ & 70,0 \\
\hline
\end{tabular}

(') Análises efetuadas no laboratório do Centro de Solos e Recursos Agroambientais, Instituto Agronômico, Campinas.
As características agronômicas descritas foram inicialmente submetidas à análise da variância, em cada experimento, em 1999 e 2000, utilizando-se o teste F, ao nível de 5\%, a fim de detectar efeitos significativos dos genótipos e das repetições (Gomes, 2000).

Efetuaram-se análises conjuntas da variância dos dois experimentos, visando detectar, pelo teste $\mathrm{F}$ ao nível de $5 \%$, as significâncias dos efeitos de genótipos, anos e interação genótipos $\mathrm{x}$ anos.

O teste de Tukey, ao nível de 5\%, foi empregado para comparar as médias dos genótipos em cada um dos parâmetros avaliados, em cada experimento e no grupo de experimentos, usando-se como estimativa do desvio-padrão residual o quadrado médio da interação genótipos $\mathrm{x}$ anos da análise conjunta.

Calcularam-se as porcentagens de redução da produção de grãos, de cada genótipo, de 2000 em relação a 1999, a fim de avaliar os efeitos das geadas ocorridas em 2000.

Para os anos considerados (1999 e 2000), visando estimar o grau de associação entre as características agronômicas avaliadas nos genótipos de trigo, foram 
calculadas correlaçôes simples, pelo teste t ao nível de $5 \%$, considerando-se os dados obtidos nas 80 parcelas.

\section{RESULTADOS E DISCUSSÃO}

As produções médias de grãos, $\mathrm{kg} \cdot \mathrm{ha}^{-1}$, bem como as porcentagens de redução da produção de grãos dos genótipos de trigo estudados nos experimentos instalados em irrigação por aspersão, na Estação Experimental de Agronomia de Tatuí, em 1999 e 2000, encontram-se no quadro 3.

O resultado da análise da variância do experimento instalado em 1999, quando não houve ocorrência de geadas, mostrou efeito significativo para os genótipos e não significativo para as repetições. Aplicando-se o teste de Tukey, ao nível de 5\%, para a comparação das médias dos genótipos, observou-se que o 7 foi o mais produtivo (5.549 kg.ha-1), diferindo apenas dos genótipos 3, 9, 10,14 e da cultivar-controle IAC-24.

Em 2000, houve uma drástica redução na produção de grãos dos genótipos de trigo em relação ao ano anterior, em virtude da ocorrência de geadas. Em julho de 2000, conforme dados fornecidos pelo Centro de Ecofisiologia e Biofísica do IAC, foram registradas, no abrigo, temperaturas mínimas absolutas baixas nos dias $17\left(-1,4^{\circ} \mathrm{C}\right), 18\left(-1,2^{\circ} \mathrm{C}\right), 21\left(-2,0^{\circ} \mathrm{C}\right)$ e $22\left(-1,8^{\circ} \mathrm{C}\right)$, caracterizando a ocorrência de geadas durante o período de enchimento dos grãos. As temperaturas mínimas na relva em 17 e 18 de julho foram ao redor de $-7^{\circ} \mathrm{C}$, prejudicando sensivelmente a cultura do trigo.

Comparando-se os genótipos de trigo, pelo teste de Tukey ao nível de 5\%, constatou-se que a linhagem 1 foi a mais produtiva $\left(2.944 \mathrm{~kg}^{\mathrm{k}} \mathrm{ha}^{-1}\right)$, diferindo apenas das linhagens 2, 7, 14 e da cultivar- controle IAC-24 do experimento de 2000, demonstrando ser a menos prejudicada pelas geadas ocorridas.

Considerando-se em conjunto os dois ensaios (1999 e 2000), instalados em Tatuí, não se verificaram diferenças significativas entre os genótipos em relação à produção de grãos em vista da significativa interação genótipos $\mathrm{x}$ anos. Provavelmente, essa interação significativa deve-se à ocorrência das geadas, o que

Quadro 3. Produção média de grãos dos genótipos de trigo avaliados nos experimentos instalados, em condição de irrigação por aspersão, na Estação Experimental de Agronomia de Tatuí, em 1999 e 2000

\begin{tabular}{|c|c|c|c|c|}
\hline \multirow[t]{2}{*}{ Genótipos } & \multicolumn{3}{|c|}{ Produção de grãos } & \multirow[t]{2}{*}{ Redução $^{(1}$} \\
\hline & 1999 & 2000 & Média & \\
\hline & - & - kg.ha ${ }^{-1}$ & - & $\%$ \\
\hline 1 & $5.014 \mathrm{a}-\mathrm{d}$ & $2.944 \mathrm{a}$ & 3.979 & 41,28 \\
\hline 2 & $4.528 \mathrm{a}-\mathrm{d}$ & $1.424 \mathrm{~b}$ & 2.976 & 68,55 \\
\hline 3 & $4.319 \mathrm{~cd}$ & $2.139 \mathrm{ab}$ & 3.229 & 50,48 \\
\hline 4 & $5.132 \mathrm{a}-\mathrm{c}$ & $1.909 \mathrm{ab}$ & 3.521 & 62,80 \\
\hline 5 & $5.021 \mathrm{a}-\mathrm{c}$ & $2.007 \mathrm{ab}$ & 3.514 & 60,03 \\
\hline 6 & $5.132 \mathrm{a}-\mathrm{c}$ & $1.910 \mathrm{ab}$ & 3.521 & 62,79 \\
\hline 7 & $5.549 \mathrm{a}$ & $1.563 \mathrm{~b}$ & 3.556 & 71,84 \\
\hline 8 & $5.452 \mathrm{ab}$ & $2.334 \mathrm{ab}$ & 3.893 & 57,20 \\
\hline 9 & $4.278 \mathrm{~cd}$ & $1.820 \mathrm{ab}$ & 3.049 & 57,47 \\
\hline 10 & $4.410 \mathrm{~b}-\mathrm{d}$ & $1.993 \mathrm{ab}$ & 3.201 & 54,81 \\
\hline 11 & $5.333 \mathrm{a}-\mathrm{c}$ & $1.917 \mathrm{ab}$ & 3.625 & 64,07 \\
\hline 12 & $5.326 \mathrm{a}-\mathrm{c}$ & $2.194 \mathrm{ab}$ & 3.760 & 58,81 \\
\hline 13 & $4.875 \mathrm{a}-\mathrm{d}$ & $1.847 \mathrm{ab}$ & 3.361 & 62,11 \\
\hline 14 & $4.326 \mathrm{~cd}$ & $1.313 \mathrm{~b}$ & 2.819 & 69,66 \\
\hline 15 & $5.160 \mathrm{a}-\mathrm{c}$ & $2.313 \mathrm{ab}$ & 3.736 & 55,18 \\
\hline 16 & $4.493 \mathrm{a}-\mathrm{d}$ & $2.372 \mathrm{ab}$ & 3.433 & 47,20 \\
\hline 17 & $5.222 \mathrm{a}-\mathrm{c}$ & $1.646 \mathrm{ab}$ & 3.434 & 68,48 \\
\hline 18 & $4.833 \mathrm{a}-\mathrm{d}$ & $1.979 \mathrm{ab}$ & 3.406 & 59,05 \\
\hline IAC-24 & $3.903 \mathrm{~d}$ & $1.396 \mathrm{~b}$ & 2.649 & 64,23 \\
\hline IAC-289 & $4.889 \mathrm{a}-\mathrm{d}$ & $1.938 \mathrm{ab}$ & 3.413 & 60,37 \\
\hline$\overline{\mathrm{F} \text { (Genótipos) }}$ & $4,65^{*}$ & $2,44^{*}$ & 1,88 & - \\
\hline$F($ Anos $)$ & - & - & $685,49^{*}$ & - \\
\hline F (Genótipos $\mathrm{x}$ anos) & - & - & $1,85^{*}$ & - \\
\hline d.m.s. (Tukey a 5\%) & 1113 & 1303 & 1430 & - \\
\hline CV (\%) & 8,72 & 25,48 & 15,16 & - \\
\hline
\end{tabular}

Médias seguidas de uma letra em comum não diferem pelo teste de Tukey ao nível de 5\%. ( ${ }^{1}$ ) Redução da produção de grãos dos genótipos analisada em 2000 em relação a 1999. *: Significativo ao nível de 5\%. 
influenciou o comportamento dos genótipos em relação à produção de grãos, haja vista que a linhagem 7 foi a mais produtiva em $1999\left(5.549 \mathrm{~kg} \cdot \mathrm{ha}^{-1}\right)$ e uma das menos produtivas em 2000 (1.563 kg.ha-1).

De maneira geral, constatou-se que as geadas foram prejudiciais a todos os genótipos de trigo, causando reduçôes na produção de 41,3\% a 71,8\% (Quadro 3).

No quadro 4 encontram-se a altura média das plantas $(\mathrm{cm})$ e o número de grãos por espiga dos genótipos de trigo avaliados em 1999 e 2000 e o ciclo da emergência ao florescimento (dias) obtido em 2000, em Tatuí.

Os resultados da análise conjunta demonstraram a ocorrência da interação significativa genótipos $\mathrm{x}$ anos para altura das plantas, indicando que houve variação na altura dos genótipos em função dos anos. Apesar da interação, o genótipo 3 apresentou as plantas mais altas em 1999, 2000 e quando se consideraram os dois experimentos em conjunto. Por outro lado, os genótipos $9(81 \mathrm{~cm})$ e $7(71 \mathrm{~cm})$ apresentaram plantas mais baixas nos experimentos de 1999 e 2000 respectivamente. Os genótipos 9 e 13 exibiram portes mais baixos quando os dois experimentos foram considerados.

Os genótipos avaliados floresceram, em 2000, entre 19 de junho e 3 de julho, período em que não ocorreram geadas, conforme dados apresentados, favorecendo, portanto, a formação dos grãos. Observase no quadro 4 que o genótipo 1 foi o mais tardio (76 dias) e o genótipo 11, o mais precoce (62 dias) para o florescimento.

Os genótipos 2, 9, 14 e 18 e a cultivar IAC-289 exibiram espigas com maior número de grãos, não diferindo dos genótipos 1, 4, 5, 6, 7, 8, 10, 15 e 16 em 1999. Não se verificaram diferenças significativas para essa característica entre os genótipos em 2000, pelo teste $\mathrm{F}$ ao nível de $5 \%$, devido a um elevado erro residual. Observaram-se diferenças significativas entre os genótipos quando se consideraram os dois anos. $\mathrm{O}$ genótipo 14 apresentou maior número de grãos por espiga $(48,9)$, diferindo apenas, pelo teste de Tukey ao nível de 5\%, dos genótipos 3, 12 e 17 .

Quadro 4. Altura média das plantas, ciclo da emergência ao florescimento e número de grãos por espiga dos genótipos de trigo avaliados, em condição de irrigação por aspersão, na Estação Experimental de Agronomia de Tatuí

\begin{tabular}{|c|c|c|c|c|c|c|c|}
\hline \multirow[t]{3}{*}{ Genótipos } & \multicolumn{3}{|c|}{ Altura das plantas } & Ciclo & \multicolumn{3}{|c|}{ Grãos/espiga } \\
\hline & & & & \multirow{2}{*}{$\frac{\text { Emerg.-Floresc. }}{2000}$} & & \multirow[b]{2}{*}{2000} & \multirow[b]{2}{*}{ Média } \\
\hline & 1999 & 2000 & Média & & 1999 & & \\
\hline & & $\mathrm{cm}-$ & & dias & & $\mathrm{n}^{\mathrm{o}}$ & \\
\hline 1 & $98 \mathrm{ab}$ & $83 a-c$ & $90 \mathrm{ab}$ & $76 \mathrm{a}$ & 44,1 a-f & 43,8 & $44,0 \mathrm{a}-\mathrm{c}$ \\
\hline 2 & $86 \mathrm{~d}-\mathrm{f}$ & $79 \mathrm{~b}-\mathrm{d}$ & $83 \mathrm{bc}$ & $69 \mathrm{~b}-\mathrm{f}$ & $51,3 \mathrm{a}$ & 41,2 & $46,2 \mathrm{a}-\mathrm{c}$ \\
\hline 3 & $104 \mathrm{a}$ & $91 \mathrm{a}$ & $97 \mathrm{a}$ & $64 \mathrm{e}-\mathrm{g}$ & $29,0 \mathrm{~g}$ & 34,8 & $31,9 \mathrm{~d}$ \\
\hline 4 & $91 \mathrm{~b}-\mathrm{e}$ & $78 \mathrm{~b}-\mathrm{d}$ & $85 \mathrm{bc}$ & $73 a-c$ & $46,3 a-c$ & 45,9 & 46,1 a-c \\
\hline 5 & $93 \mathrm{~b}-\mathrm{d}$ & $80 \mathrm{~b}-\mathrm{d}$ & $87 \mathrm{a}-\mathrm{c}$ & $65 e-g$ & 42,2 a-f & 43,2 & 42,7 a-d \\
\hline 6 & $87 \mathrm{c}-\mathrm{f}$ & $75 \mathrm{~b}-\mathrm{d}$ & $81 \mathrm{bc}$ & 70 a-e & $47,7 \mathrm{a}-\mathrm{c}$ & 49,0 & $48,4 \mathrm{ab}$ \\
\hline 7 & $90 \mathrm{~b}-\mathrm{e}$ & $71 \mathrm{~d}$ & $81 \mathrm{bc}$ & $64 \mathrm{e}-\mathrm{g}$ & 42,1 a-f & 37,0 & 39,6 a-d \\
\hline 8 & $90 \mathrm{~b}-\mathrm{e}$ & $80 \mathrm{~b}-\mathrm{d}$ & $85 \mathrm{bc}$ & $74 \mathrm{ab}$ & $45,8 \mathrm{a}-\mathrm{d}$ & 43,2 & 44,5 a-c \\
\hline 9 & $81 \mathrm{f}$ & $73 \mathrm{~cd}$ & $77 \mathrm{c}$ & $72 \mathrm{a}-\mathrm{d}$ & $50,6 \mathrm{a}$ & 44,0 & $47,3 \mathrm{ab}$ \\
\hline 10 & $95 \mathrm{bc}$ & $85 \mathrm{ab}$ & $90 \mathrm{ab}$ & $74 \mathrm{ab}$ & $48,3 \mathrm{ab}$ & 39,5 & 43,9 a-c \\
\hline 11 & $91 \mathrm{~b}-\mathrm{e}$ & $76 \mathrm{~b}-\mathrm{d}$ & $84 \mathrm{bc}$ & $62 \mathrm{~g}$ & $38,4 \mathrm{~b}-\mathrm{f}$ & 36,0 & 37,2 a-d \\
\hline 12 & $91 \mathrm{~b}-\mathrm{e}$ & $78 \mathrm{~b}-\mathrm{d}$ & $85 \mathrm{bc}$ & $74 \mathrm{ab}$ & $36,1 \mathrm{~d}-\mathrm{g}$ & 37,7 & $36,9 \mathrm{~b}-\mathrm{d}$ \\
\hline 13 & 84 ef & $72 \mathrm{~d}$ & $78 \mathrm{c}$ & $63 \mathrm{fg}$ & $38,0 \mathrm{c}-\mathrm{f}$ & 37,3 & 37,6 a-d \\
\hline 14 & $86 \mathrm{~d}-\mathrm{f}$ & $76 \mathrm{~b}-\mathrm{d}$ & $81 \mathrm{bc}$ & $74 \mathrm{ab}$ & $50,9 \mathrm{a}$ & 47,0 & $48,9 \mathrm{a}$ \\
\hline 15 & $98 \mathrm{ab}$ & $79 \mathrm{~b}-\mathrm{d}$ & $89 \mathrm{ab}$ & 72 a-d & 45,1 a-e & 45,7 & $45,4 a-c$ \\
\hline 16 & $85 \mathrm{~d}-\mathrm{f}$ & $75 \mathrm{~b}-\mathrm{d}$ & $80 \mathrm{bc}$ & $66 \mathrm{~d}-\mathrm{g}$ & 45,9 a-d & 45,4 & $45,6 \mathrm{a}-\mathrm{c}$ \\
\hline 17 & $87 c-f$ & $74 \mathrm{~cd}$ & $80 \mathrm{bc}$ & 70 a-e & $35,0 \mathrm{e}-\mathrm{g}$ & 34,8 & $34,9 \mathrm{~cd}$ \\
\hline 18 & $88 \mathrm{c}-\mathrm{f}$ & $83 a-c$ & $86 \mathrm{bc}$ & $68 \mathrm{~b}-\mathrm{g}$ & $49,0 \mathrm{a}^{\circ}$ & 47,5 & $48,2 \mathrm{ab}$ \\
\hline IAC-24 & $93 \mathrm{~b}-\mathrm{d}$ & $76 \mathrm{~b}-\mathrm{d}$ & $85 \mathrm{bc}$ & $67 c-g$ & $34,8 \mathrm{fg}$ & 40,0 & $37,4 \mathrm{a}-\mathrm{d}$ \\
\hline IAC-289 & $95 \mathrm{bc}$ & $78 \mathrm{~b}-\mathrm{d}$ & $86 \mathrm{bc}$ & $68 \mathrm{~b}-\mathrm{g}$ & $48,9 a$ & 43,8 & 46,3 a-c \\
\hline F (Genótipos) & $10,93^{*}$ & $5,12^{*}$ & $6,41^{*}$ & $8,85^{*}$ & $10,55^{*}$ & 1,28 & $6,13^{*}$ \\
\hline F (Anos) & - & - & $220,79^{*}$ & - & - & - & 3,11 \\
\hline F (Genótipos x anos) & - & - & $1,80^{*}$ & - & - & - & 0,89 \\
\hline d.m.s. (Tukey a 5\%) & 9 & 11 & 11 & 7 & 10,2 & 20,6 & 11,8 \\
\hline CV (\%) & 3,66 & 5,40 & 4,71 & 4,15 & 8,97 & 18,72 & 14,36 \\
\hline
\end{tabular}

Médias seguidas de uma letra em comum não diferem pelo teste de Tukey ao nível de 5\%. *: Significativo ao nível de 5\%. 
A massa de cem grãos e as características morfológicas dos grãos dos genótipos de trigo avaliados nos experimentos instalados em Tatuí, encontram-se no quadro 5.

Em virtude da significativa interação genótipos $\mathrm{x}$ anos, não houve diferença entre a média da massa de cem grãos quando se consideraram os dois anos, provavelmente, ocasionada pelas geadas em 2000 . Nesse mesmo ano, observou-se também que a maioria dos genótipos de trigo apresentou redução na massa de grãos, em comparação a 1999.

O genótipo 3 foi o que apresentou grãos mais pesados $(4,90 \mathrm{~g})$ em 1999, não diferindo apenas, pelo teste de Tukey, dos genótipos 7, 12 e 17. Em 2000, o genótipo 1 mostrou maior massa de cem grãos $(4,67$ g), diferindo dos genótipos 5, 9, 10, 13, 14, 16, 18 e da cultivar IAC-24.

O genótipo 17 apresentou grãos mais compridos $(6,7 \mathrm{~mm})$. O genótipo 1 destacou-se por apresentar os grãos mais largos (3,4 mm). Não foram detectadas, pelo teste de Tukey, diferenças entre as médias dos genótipos em relação à espessura dos grãos.
Observou-se que os coeficientes de variação em 2000 foram mais altos que os de 1999 para produção de grãos, número de grãos por espiga e massa de cem grãos, sugerindo a ocorrência de geadas como a principal responsável por essa variação.

As correlações simples entre produção de grãos, altura das plantas, número de grãos por espiga e massa de cem grãos, independentemente dos genótipos de trigo e das repetições no experimento de 1999, são apresentadas no quadro 6 .

Em 1999, observou-se que as correlações entre massa de cem grãos e a produção de grãos $\left(0,262^{*}\right)$ e entre massa de cem grãos e altura da planta $\left(0,283^{*}\right)$ foram significativas e positivas, isto é, houve uma tendência de que quanto maior a massa dos grãos, mais altas e produtivas seriam as plantas. A altura das plantas, em 1999, não foi correlacionada com a produção de grãos. Por outro lado, a correlação entre a massa de cem grãos e o número de grãos por espiga foi significativa e negativa $\left(-0,483^{*}\right)$, mostrando uma tendência de que quanto mais grãos havia na espiga, menor era sua massa. Correlações significativas e positivas foram obtidas no experimento instalado em 2000 (Quadro

Quadro 5. Massa média de cem grãos e características morfológicas dos grãos dos genótipos de trigo avaliados, em condição de irrigação por aspersão, na Estação Experimental de Agronomia de Tatuí

\begin{tabular}{|c|c|c|c|c|c|c|}
\hline \multirow[t]{2}{*}{ Genótipos } & \multicolumn{3}{|c|}{ Massa de cem grãos } & \multicolumn{3}{|c|}{ Grãos $^{(1)}$} \\
\hline & 1999 & 2000 & Média & Comprimento & Largura & Espessura \\
\hline & & $\mathrm{g}-$ & 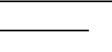 & 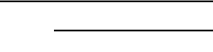 & $-\mathrm{mm}$ & 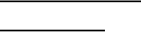 \\
\hline 1 & $4,03 \mathrm{~d}-\mathrm{i}$ & $4,67 \mathrm{a}$ & 4,35 & $6,5 a-c$ & $3,6 \mathrm{a}$ & 3,0 \\
\hline 2 & $3,61 \mathrm{~g}-\mathrm{j}$ & $3,62 \mathrm{ab}$ & 3,62 & $6,3 \mathrm{a}-\mathrm{d}$ & 3,1 a-d & 2,9 \\
\hline 3 & $4,90 \mathrm{a}$ & $3,61 \mathrm{ab}$ & 4,26 & $6,5 a-c$ & 2,9 a-d & 2,9 \\
\hline 4 & $3,84 \mathrm{e}-\mathrm{i}$ & $3,38 \mathrm{ab}$ & 3,61 & $6,0 \mathrm{~cd}$ & 3,0 a-d & 2,5 \\
\hline 5 & $4,10 \mathrm{~b}-\mathrm{h}$ & $2,62 \mathrm{~b}$ & 3,36 & $5,9 \mathrm{~d}$ & $2,7 \mathrm{~cd}$ & 2,6 \\
\hline 6 & $4,26 \mathrm{~b}-\mathrm{e}$ & $3,58 \mathrm{ab}$ & 3,92 & $6,3 \mathrm{a}-\mathrm{d}$ & 3,0 a-d & 2,7 \\
\hline 7 & $4,53 \mathrm{a}-\mathrm{c}$ & $3,31 \mathrm{ab}$ & 3,92 & $6,1 \mathrm{~b}-\mathrm{d}$ & $3,1 \mathrm{a}-\mathrm{d}$ & 2,7 \\
\hline 8 & $3,74 \mathrm{e}-\mathrm{j}$ & $3,18 \mathrm{ab}$ & 3,46 & $6,0 \mathrm{~cd}$ & 3,1 a-d & 2,8 \\
\hline 9 & $3,63 \mathrm{f}-\mathrm{j}$ & $2,55 \mathrm{~b}$ & 3,09 & $6,1 \mathrm{~b}-\mathrm{d}$ & $2,8 \mathrm{~b}-\mathrm{d}$ & 2,5 \\
\hline 10 & $3,16 j$ & $2,81 \mathrm{~b}$ & 2,99 & $6,1 \mathrm{~b}-\mathrm{d}$ & 3,1 a-d & 2,8 \\
\hline 11 & $4,23 \mathrm{~b}-\mathrm{e}$ & $3,16 \mathrm{ab}$ & 3,70 & $6,3 \mathrm{a}-\mathrm{d}$ & $2,9 \mathrm{a}-\mathrm{d}$ & 2,7 \\
\hline 12 & 4,46 a-d & $3,57 \mathrm{ab}$ & 4,01 & $6,6 \mathrm{ab}$ & $3,3 \mathrm{a}-\mathrm{d}$ & 2,7 \\
\hline 13 & $3,97 \mathrm{c}-\mathrm{i}$ & $3,00 \mathrm{~b}$ & 3,48 & $6,0 \mathrm{~cd}$ & 2,9 a-d & 2,5 \\
\hline 14 & $3,48 \mathrm{ij}$ & $2,89 \mathrm{~b}$ & 3,19 & $6,0 \mathrm{~cd}$ & $3,0 \mathrm{a}-\mathrm{d}$ & 2,6 \\
\hline 15 & $3,99 \mathrm{~b}-\mathrm{i}$ & $3,64 \mathrm{ab}$ & 3,81 & $6,3 \mathrm{a}-\mathrm{d}$ & $3,5 \mathrm{ab}$ & 2,9 \\
\hline 16 & $3,53 \mathrm{~h}-\mathrm{j}$ & $2,53 \mathrm{~b}$ & 3,03 & $5,8 \mathrm{~d}$ & $2,6 \mathrm{~b}$ & 2,6 \\
\hline 17 & $4,56 \mathrm{ab}$ & $3,31 \mathrm{ab}$ & 3,94 & $6,7 \mathrm{a}$ & 2,9 a-d & 2,7 \\
\hline 18 & $4,21 \mathrm{~b}-\mathrm{f}$ & $2,66 \mathrm{~b}$ & 3,43 & $6,3 \mathrm{a}-\mathrm{d}$ & $2,6 \mathrm{~d}$ & 2,6 \\
\hline IAC-24 & $4,19 \mathrm{~b}-\mathrm{g}$ & $2,71 \mathrm{~b}$ & 3,45 & $5,8 \mathrm{~d}$ & 3,0 a-d & 2,8 \\
\hline IAC-289 & $3,91 \mathrm{~d}-\mathrm{i}$ & $3,59 \mathrm{ab}$ & 3,75 & $6,0 \mathrm{~cd}$ & $3,4 a-c$ & 2,9 \\
\hline F (Genótipos) & $14,17^{*}$ & $2,80^{*}$ & 1,9 & $5,61^{*}$ & $3,06^{*}$ & $2,12^{*}$ \\
\hline $\mathrm{F}($ Anos) & - & - & $40,95^{*}$ & - & - & - \\
\hline F (Genótipos $\mathrm{x}$ anos) & - & - & $2,46^{*}$ & - & - & - \\
\hline d.m.s. (Tukey a 5\%) & 0,59 & 1,64 & 1,61 & 0,6 & 0,8 & 0,5 \\
\hline $\mathrm{CV}(\%)$ & 5,60 & 19,46 & 13,90 & 3,44 & 10,27 & 7,45 \\
\hline
\end{tabular}

Médias seguidas de uma letra em comum não diferem pelo teste de Tukey ao nível de 5\%. (1) Avaliados apenas em 2000. *: Significativo ao nível de $5 \%$. 
7) entre produção de grãos com altura da planta $\left(0,260^{*}\right)$, produção de grãos com massa de cem grãos $\left(0,301^{*}\right)$ e produção de grãos com largura dos grãos $\left(0,254^{*}\right)$, indicando que as plantas mais altas, com maior massa $\mathrm{e}$ grãos largos resultaram em maiores produções.

Correlações significativas e negativas foram encontradas entre o número de grãos por espiga e o comprimento dos grãos $\left(-0,265^{*}\right)$ e entre o número de grãos por espiga e a espessura dos grãos $\left(-0,260^{*}\right)$, indicando que quanto mais compridos e espessos os grãos, menor era o número de grãos na espiga.
Quadro 6. Estimativas das correlaçôes simples entre as características agronômicas avaliadas no experimento instalado em condição de irrigação por aspersão, na Estação Experimental de Agronomia de Tatuí, em 1999

\begin{tabular}{lccc}
\hline Características & $\begin{array}{c}\text { Produção } \\
\text { de grãos }\end{array}$ & $\begin{array}{c}\text { Altura das } \\
\text { plantas }\end{array}$ & $\begin{array}{c}\text { Grãos } \\
\text { por espiga }\end{array}$ \\
\hline Altura das plantas & $-0,008$ & - & - \\
Grãos por espiga & $-0,136$ & $-0,200$ & - \\
Massa de cem grãos & $0,262^{*}$ & $0,283^{*}$ & $-0,483^{*}$ \\
\hline
\end{tabular}

*: Significativo ao nível de 5\%.

Quadro 7. Estimativas das correlações simples entre as características agronômicas avaliadas, no experimento instalado em condiçãoo de irrigação por aspersão, na Estação Experimental de Agronomia de Tatuí, em 2000

\begin{tabular}{llccccc}
\hline Características & $\begin{array}{c}\text { Produção } \\
\text { de grãos }\end{array}$ & $\begin{array}{c}\text { Altura das } \\
\text { plantas }\end{array}$ & $\begin{array}{c}\text { Grãos por } \\
\text { espiga }\end{array}$ & $\begin{array}{c}\text { Massa de } \\
\text { cem grãos }\end{array}$ & $\begin{array}{c}\text { Comprimento } \\
\text { dos grãos }\end{array}$ & $\begin{array}{c}\text { Largura } \\
\text { dos grãos }\end{array}$ \\
\hline Altura das plantas & $0,260^{*}$ & - & - & - & - & - \\
Grãos por espiga & 0,141 & 0,137 & - & - & - & - \\
Massa de cem grãos & $0,301^{*}$ & $-0,119$ & $-0,108$ & - & - & - \\
Comprimento dos grãos & 0,211 & 0,147 & $-0,265^{*}$ & $0,463^{*}$ & - & - \\
Largura dos grãos & $0,254^{*}$ & $-0,140$ & 0,092 & $0,801^{*}$ & $0,271^{*}$ & - \\
Espessura dos grãos & 0,133 & 0,038 & $-0,260^{*}$ & $0,710^{*}$ & $0,378^{*}$ & $0,719^{*}$ \\
\hline
\end{tabular}

*: Significativo ao nível de 5\%.

A massa de cem grãos correlacionou-se significativa e positivamente com o comprimento, a largura e a espessura dos grãos $\left(0,463^{*}, 0,801^{*}\right.$ e $\left.0,710^{*}\right)$, isto é, plantas com grãos mais compridos, largos e espessos resultaram em maior massa de grãos.

\section{CONCLUSÕES}

1. As geadas ocorridas na época do enchimento dos grãos ocasionaram redução na produção em todos os genótipos de trigo avaliados. Redução no número de grãos por espiga e na massa de cem grãos também foram verificadas na maioria dos genótipos estudados.

2. Houve uma tendência de os genótipos altos serem menos afetados, ou terem escapado da ação das geadas, apresentando portanto, menores perdas na produção de grãos.

3. Em 1999, destacaram-se o genótipo 9 pelo porte baixo, os genótipos 2, 9 e 14 pelo maior número de grãos por espiga e o genótipo 3, pela maior massa de cem grãos, constituindo-se em fontes genéticas dessas características para programas de cruzamentos.

\section{AGRADECIMENTOS}

À Fundação de Amparo à Pesquisa do Estado de São Paulo (FAPESP), pela concessão de bolsa de mestrado para a realização deste trabalho e aos pesquisadores científicos Antônio Wilson Penteado Ferreira Filho e
Maria Elisa A.G. Zagatto Paterniani, do IAC, pelas sugestões apresentadas na elaboração deste artigo.

\section{REFERÊNCIAS BIBLIOGRÁFICAS}

BANATH C.L.; SINGLE W.V. Frost injury to wheat stems and grain production. Australian Journal Agriculture Research, Melbourne, v.27, p.749-53, Nov.1976.

FELICIO, J.C.; CAMARGO, C.E.O.; FERREIRA-FILHO, A.W.P.; FREITAS, J.G.; BARROS, B.C.; VITTI, P. Tocantins (IAC-23) e Tucuruí (IAC-24). Novos cultivares de trigo. Bragantia, Campinas, v.47, n.1, p.93-107, 1988.

FELICIO, J.C.; CAMARGO, C.E.O.; VITTI P.; CAMPAGNOLLI, D.M.F. Comportamento agronômico e avaliação tecnológica dos cultivares de trigo IAC-120 (Curumi), IAC-286 (Takaoka) e IAC-289 (Marruá) para o Estado de São Paulo. Bragantia, Campinas, v.53, n.2, p.191-208, 1994.

GOMES, F.P. Curso de estatistica experimental. 14.ed. Piracicaba: Livraria Nobel, 2000. 477p.

MOTA, F.S. Clima e zoneamento para a triticultura no Brasil. In: Fundaçāo Cargill, Trigo no Brasil. Campinas, 1982. v.1, p.27-61.

RAIJ. B. van; CANTARELLA, H.; QUAGGIO, J.A.; FURLANI, A.M.C. In: Recomendaçôes de adubação e calagem para o Estado 
de São Paulo. Campinas: Instituto Agronômico/Fundação IAC, 1997. 285p. (Boletim técnico, 100)

SCHEEREN, P.L. Danos de geada em trigo: avaliação preliminar de cultivares. Pesquisa Agropecuária Brasileira,
Brasília, v.17, n.6, p.853-858, jun.1982.

SINGLE W.V. Frost damage in wheat crops. The Agricultural Gazette of New South Wales, Sidney, v.82, n.3, p.211-14, 1971. 